\title{
Predator-Prey Model for Noctiluca Stillans sp. and Acartia sp.
}

\author{
Apisit Jitman, Natdanai Chailangka, Sineenart Srimongkol* \\ Department of Mathematics, Faculty of Science, Burapha University, \\ Mueng, Chonburi, 20131 \\ Thailand \\ ${ }^{*}$ Corresponding author, e-mail:sineenart@buu.ac.th
}

Received: April 15, 2021. Revised: Novemeber 22, 2021. Accepted: December 29, 2021. Published: January 31, 2022.

\begin{abstract}
In this paper, we have an intention to study about application of mathematical modeling Predator-Prey model to Noctiluca scintillans which is the principal to occur plankton bloom phenomenon in Bangsaen, Thailand where the authors live. We examine Noctiluca scintillans in a prey role meanwhile Arcatia sp. is chosen to be a predator role and observe the results by Lotka Voltera Predator-Prey model though numerical calculation using Python programming.
\end{abstract}

Keywords- Noctiluca Scintillans, Acartia, predatory-prey model, plankton bloom

\section{INTRODUCTION}

$\mathrm{T}$ HE huge accumulation of phytoplankton, macroalgae and colorless heterotrophic protists can change the color of water, cover the surface, make toxicity to ecology $([14])$. In the gulf of Thailand, the N. scintillans is the most popular phytoplankton such that accumulate and bloom. Since the authors live in Bangsaen district of Chonburi which is part of gulf of Thailand, we face the plankton bloom phenomenon almost every year. The sea is fulled by accumulated N. scintillans, so it incur toxicity which is globally known as dead sea. Dead creatures of the sea lay whole the beach. Furthermore, it also produce air pollution which annoy the tourists. We have an intention to apply mathematical model to study incidence of this phenomenon in predator and prey role. Moreover, the principal of this phenomenon is N. scintillans. Therefore, we are going to add it to this work.

N. scintiilans or Noctiluca scintillans was classified into the jellyfish until Haeckel decided to move it to the crystoflagellates with the dinoflagellates in 1873 . N. scintillans is a single-celled spheroid organism and its ranging from is around 400 to $1500 \mu \mathrm{m}$ in length. It can not really swim but can move with the current. N. scintillans can exist in a green or red form only, depending on the pigmentation in its vacuoles. It can be found worldwide. Precisely, N. scintillans has a significant place in the pelagic food chain. N. scintillans is preyed upon by many copepods such as Calanus sp., Temora sp. and Acartia sp. Because of its excessive proliferation, it always attract many predators due to its very dense aggregations and it frequent bioluminescence in phase of its life.

Acartia is known as a genus of marine calanoid copepods. They are epipelagic, estuarine, zooplanktonic found throughout the oceans of the world, primarily in temperate regions. When Acatia was just egg or larva, it was preyed by N. scintillans. But if it grow up, the role play is switched [1] .

In 1968-1988, G.Uhlig and G.Sahling [13] studied about seasonal development of N. scintillans with continuous monitoring at a Helgoland-Roads over a period of 20 years. They revealed that the spatial distribution of Noctiluca as determined every year in July, serves as a realistic base for biomass calculations.

In 1998, Y. Nakamura [9] has published Growth and grazing of a large of heterotrophic dinoflagellate, Noctiluca scintillans, in laboratory cultures which it is studying about examining the growth of N. scintiilans in his laboratory.

In 2003-2004, T. Lirdwitayaprasit, S. Meksumpun, S. Rungsupa and K. Furuya [8] studied the seasonal variations in cell abundance of $\mathrm{N}$. scintillans though eight station of the coastal waters of Chonburi Province, the upper gulf of Thailand.

In 2015, M. Freilich [2] used non-dimensional parameters to develop general principal of bloom dynamic with limited light that could test against empirical results.

In 2021, Zhang, Shuwen and Xia, Xiaomin and Ke, Ying and Song, Shuqun and Shen, Zhuo and Cheung, Shunyan and Liu, Hongbin [15 had long survey to conduct in Port Shelter, a subtropical coastal water in NW Pacific, beginning before Noctiluca scintillans and Mesodium rubrum blooms.

Recently, the survey research in English showed that harmful algal bloom on shellfish, the toxins in mussel can have severe ecological, human health, and seafood industry [10]. Therefore, the study of plankton is crucial. 


\section{Mathematical Model}

A. Logistic Model

The nonlinear equation

$$
P_{n+1}=r P_{n}\left(1-\frac{P_{n}}{C}\right)
$$

where $r \geq 0$ and $C>0$, called the logistic equation, is a density-dependent model for the population $P_{n}$ of a species after $n$ generations [11].

\section{B. Predator-Prey Model}

Volterra wrote down the following model:

$$
\begin{gathered}
\frac{d x}{d t}=a x-b x y, \\
\frac{d y}{d t}=-c y+d x y,
\end{gathered}
$$

where $x$ and $y$ represent prey and predator populations respectively, $t$ is the time, and note that $a$ is the rate of birth of prey population, $b$ is the rate of death of prey population, $c$ is the rate of death of predator population and $d$ is rate of birth of predator population [12].

The matrix notation of the system of equations (2) and (3) is shown in the following equation,

$$
\frac{d \mathbf{x}}{d t}=\mathbf{F}
$$

where, $\mathbf{x}$ and $\mathbf{F}$ are matrix of the form

$$
\mathbf{x}=\left[\begin{array}{l}
x \\
y
\end{array}\right], \quad \mathbf{F}=\left[\begin{array}{l}
f_{1}(x, y) \\
f_{2}(x, y)
\end{array}\right]=\left[\begin{array}{c}
a x-b x y \\
-c y+d x y
\end{array}\right] .
$$

Then we will consider an eco-epidemiological system consisting of two types of species. The prey population is Noctiluca and the predator population is Acartia. For simplicity, we assume that the prey population grows logistically and the predator populations grow exponentially. Then the above model is changed as the following:

$$
\begin{gathered}
\frac{d x}{d t}=\alpha x\left(1-\frac{x}{C}\right)-\beta x y, \\
\frac{d y}{d t}=-\delta y+\gamma x y
\end{gathered}
$$

Note that

$\alpha$ is the rate of birth of prey population (Noctiluca).

$\beta$ is the rate of death of prey population (Noctiluca).

$\delta$ is the rate of death of predator population (Acartia).

$\gamma$ is the rate of birth of predator population (Acartia).

$C$ is the carrying capacity of prey population (Noctiluca).

In 1997, the growth rate of N.scintillans was examined in Nakamura's laboratory [9], so $\alpha$ is $0.2 \mathrm{cell} / \mathrm{t}$ corresponding with the study in Australia [4]. In 2009, P. Jitchum and L. Wongrat [3] studied the community structure and abundance of epipelagic copepods in a shallow protected bay, Gulf of Thailand, therefore, we obtain the rate of birth of Acartia sp. which is part of copepods such that its rate is $\delta=0.1 \mathrm{cell} / \mathrm{t}$. In fact, we
Table 1: Parameters using in the simulation.

\begin{tabular}{|c|l|}
\hline parameter & \multicolumn{1}{|c|}{ value } \\
\hline$\alpha$ & $0.2 \mathrm{cell} / \mathrm{t}$ \\
\hline$\beta$ & $0.1 \mathrm{cell} / \mathrm{t}$ \\
\hline$\delta$ & $0.4 \mathrm{cell} / \mathrm{t}$ \\
\hline$\gamma$ & $0.1 \mathrm{cell} / \mathrm{t}$ \\
\hline$C$ & $100 \mathrm{cell}$ \\
\hline
\end{tabular}

do not have information for the others, we will assume parameter rate of death of prey population and rate of death of predator population as follows $\beta$ and $\gamma$ are 0.1 and $0.4 \mathrm{cell} / \mathrm{t}$ respectively. And the last one the carrying capacity is 100 cell.

Thus, we will establish the model by satisfying the assumptions as the following:

1. The Acartia sp. which is predator must be adult state.

2. Both of N. scintillans and Acartia sp. are not allowed to migrate across territory of 1 lit of water.

\section{Qualitative Analysis}

To analyse the behavior of the system of equation (5) and (6), the steady state solutions and Jacobian Matrix are calculated. From equations (5) and (6), the steady state solutions is obtained by making the change to zero as shown in the following equations,

$$
\alpha x\left(1-\frac{x}{C}\right)-\beta x y=0,
$$

$$
-\delta y+\gamma x y=0,
$$

Solve the system of equations (7) and (8), the three steady states, $\left(\bar{x}_{1}, \bar{y}_{1}\right),\left(\bar{x}_{2}, \bar{y}_{2}\right),\left(\bar{x}_{3}, \bar{y}_{3}\right)$, are as follow:

$$
\begin{gathered}
\bar{x}_{1}=0, \quad \bar{y}_{1}=0 \\
\bar{x}_{2}=C, \quad \bar{y}_{2}=0 \\
\bar{x}_{3}=\frac{\delta}{\gamma}, \quad \bar{y}_{3}=\frac{\alpha}{\beta}\left(1-\frac{\delta}{\gamma C}\right) .
\end{gathered}
$$

To make the equations (5) and (6) linear, the Jacobian Matrix is calculated by its definition as shown in the equation (12).

$$
J=\left[\begin{array}{cc}
\alpha-\frac{2 \alpha x}{C}-\beta y & -\beta x \\
\gamma y & -\delta+\gamma x
\end{array}\right]
$$

The stability is analyzed at each steady states. For $(0,0)$, we obtain

$$
J(0,0)=\left[\begin{array}{cc}
\alpha & 0 \\
0 & -\delta
\end{array}\right] .
$$

Thus

$$
\operatorname{Tr}(J)=\alpha-\delta=-0.2,
$$




$$
\begin{gathered}
\operatorname{det}(J)=-\alpha \delta=-0.08 \\
\operatorname{disc}(J)=(\alpha-\delta)^{2}+4(\alpha \delta)=0.36
\end{gathered}
$$

namely, $\operatorname{Tr}(J)<0$ meanwhile $\operatorname{det}(j)<0$. Therefore, $(0,0)$ is a saddle point.

For $(C, 0)$, we obtain

$$
J(C, 0)=\left[\begin{array}{cc}
-\alpha & -\beta C \\
0 & -\delta+\gamma C
\end{array}\right]
$$

Thus

$$
\begin{gathered}
\operatorname{Tr}(J)=-\alpha-\delta+\gamma C=9.4, \\
\operatorname{det}(J)=-\alpha(\delta+\gamma C)=-2.08,
\end{gathered}
$$

$$
\operatorname{disc}(J)=(-\alpha-\delta+\gamma C)^{2}+4 \alpha(\delta+\gamma C)=96.68
$$

namely, $\operatorname{Tr}(J)>0$ meanwhile $\operatorname{det}(j)<0$. Therefore, $(C, 0)$ is a saddle point.

$$
\begin{aligned}
& \text { For }\left(\frac{\delta}{\gamma}, \frac{\alpha}{\beta}\left(1-\frac{\delta}{\gamma C}\right)\right), \text { we obtain } \\
& J\left(\frac{\delta}{\gamma}, \frac{\alpha}{\beta}\left(1-\frac{\delta}{\gamma C}\right)\right)=\left[\begin{array}{cc}
-\frac{\alpha \delta}{\gamma C} & -\frac{\beta \delta}{\gamma} \\
\frac{\alpha}{\beta}\left(\gamma-\frac{\delta}{C}\right) & 0
\end{array}\right] .
\end{aligned}
$$

Thus

$$
\begin{gathered}
\operatorname{Tr}(J)=-\frac{\alpha \delta}{\gamma C}=-0.008 \\
\operatorname{det}(J)=\frac{\alpha \delta}{\gamma}\left(\gamma-\frac{\delta}{C}\right)=0.0768 \\
\operatorname{disc}(J)=\left(-\frac{\alpha \delta}{\gamma C}\right)^{2}-\frac{4 \alpha \delta}{\gamma}\left(\gamma-\frac{\delta}{C}\right)=-0.076736
\end{gathered}
$$

namely, $\operatorname{Tr}(J)<0$ meanwhile $\operatorname{det}(j)>0$. Therefore, $\left(\frac{\delta}{\gamma}, \frac{\alpha}{\beta}\left(1-\frac{\delta}{\gamma C}\right)\right)$ is a stable spiral.

\section{Numerical InVEStigation}

In this section, the model in equations 5 and 6 is used predict the relation between Noctiluca and Acartia through the numerical result by Python programming. With the initial values $10 \mathrm{~N}$. scintillans cells $/ \mathrm{cm}^{3}$ and 1 Acartia cells $/ \mathrm{cm}^{3}$. The results is shown in Fig. 11. The N. scinitlllans and Acartia are oscilate when N. scinitlllans grows fast the Acartia grow slow and vice versa. The periodic solution is suit to model the behavior of the N. scinitlllans and Acartia.

The comparison of the behavior of the N. scintillans from numerical result and investigated information by Likhit, Chuchit and Chalemchia, Yoosamran ([5], [6], [7]) is presented in Fig. 2.

From figure 1 and figure 2, the trend of PredatorPrey model's graph analogous to real information even the result from model is lower than the real value.

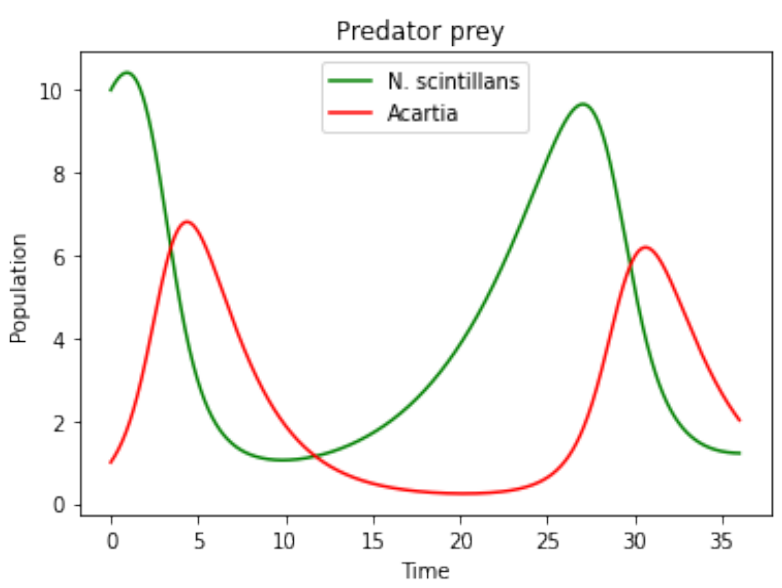

Fig. 1: Predator-Prey model predict dynamic between population of Noctiluca and Acartia $\left(\mathrm{cell} / \mathrm{cm}^{3}\right)$ where the time unit is month.

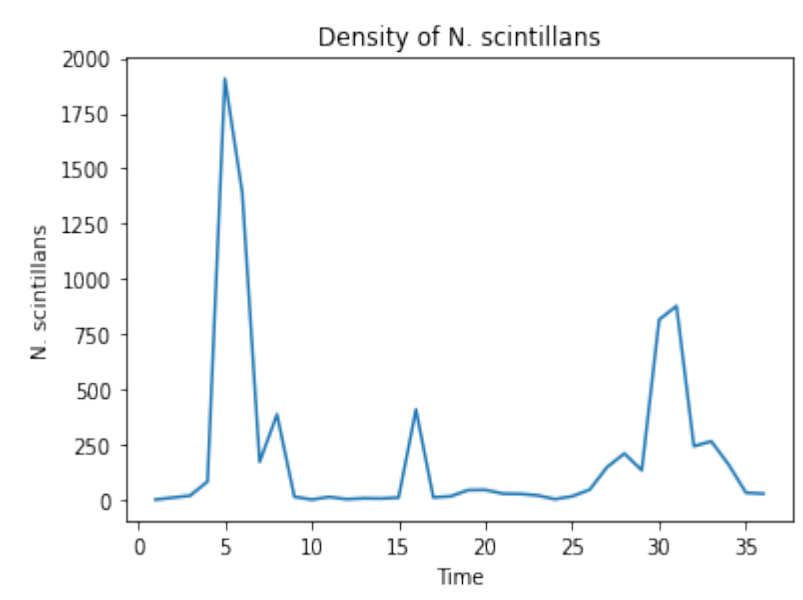

Fig. 2: Information of N. scintillans $\left(\right.$ cell $\left./ \mathrm{cm}^{3}\right)$ with continued observing 3 years. 


\section{Conclusion}

The result which is obtained from Predator-Prey model correlate highly with real investigated information. We will see the intersection between N. scintillans and Acartia sp. in Figure 1 such that there will be turning point after that. It means that if $\mathrm{N}$. scintillans is the prey and decreased into that point there will be changing to increasing rate of Predator. Then the increasing population of Acartia sp. will face the problem to consume imply the Acartia sp.'s population decrease. In technically, at the second intersection point there will arise new turning point making the N. scintillans's population highly increase. If we observe in a gap of time, this phenomenon will occur in seasoning every year but before the worst case effect from plankton bloom happen, the predator population will significantly increase and stop it promptly.

\section{ACKNOWLEDGMENT}

We would like to thank for kindly information and precious advice to Dr. Vichaya Gunbua for information of the plankton bloom in Bangsean, Thailand.

\section{REFERENCES}

[1] A. G. Durbin, E. G. Durbin, and E. Wlodarczyk. Diel feeding behavior in the marine copepod acartia tonsa in relation to food availability. Marine Ecology Progress Series, pages 23-45, 1990.

[2] M. Freilich. Mathematical Modeling of Oceanic Phytoplankton Blooms in Chaotic Flows. PhD thesis, Division of Applied Math, Brown University, 2015.

[3] P. Jitchum and L. Wongrat. Community structure and abundance of epipelagic copepods in a shallow protected bay, Gulf of Thailand. Journal of Fisheries and Environment, 33(1):28-40, 2009.

[4] P. Kelly, L. Clementson, C. Davies, S. Corney, and K. Swadling. Zooplankton responses to increasing sea surface temperatures in the southeastern australia global marine hotspot. Estuarine, Coastal and Shelf Science, 180:242-257, 2016.

[5] C. Likhit. Population dynamic of Ceratium furca and Noctiluca scintillans at Sriracha bay, Chonburi province in 2002. In Proceedings of 42th Kasetsart University Annual Conference : Fisheries.

[6] C. Likhit and Y. Chalemchia. Population dynamic of Ceratium furca and Noctiluca scintillans at Sriracha bay, Chonburi province in 2003. In Proceedings of 43th Kasetsart University Annual Conference : Fisheries.

[7] C. Likhit and Y. Chalemchia. Population dynamic of ceratium furca and noctiluca scintillans at sriracha bay, chonburi province in 2004. In Proceedings of 44th Kasetsart University Annual Conference: Fisheries.

[8] T. Lirdwitayaprasit, S. Meksumpun, S. Rungsupa, and K. Furuya. Seasonal variations in cell abundance of noctiluca scintillans in the coastal waters off chonburi province, the upper gulf of thailand. 2006 .
[9] Y. Nakamura. Growth and grazing of a large heterotrophic dinoflagellate, noctiluca scintillans, in laboratory cultures. Journal of Plankton Research, 20(9):1711-1720, 1998.

[10] A. Ross Brown, M. K. Lilley, J. Shutler, C. Widdicombe, P. Rooks, A. McEvoy, R. Torres, Y. Artioli, G. Rawle, J. Homyard, C. R. Tyler, and C. Lowe. Harmful algal blooms and their impacts on shellfish mariculture follow regionally distinct patterns of water circulation in the western english channel during the 2018 heatwave. Harmful Algae, 111:102166, 2022 .

[11] J. T. Sandefur. Discrete dynamical modeling. Oxford University Press on Demand, 1993.

[12] L. A. Segel. Mathematical models in biology (leah edelstein-keshet), 1988.

[13] G. Uhlig and G. Sahling. Long-term studies on noctiluca scintillans in the german bight population dynamics and red tide phenomena 1968-1988. Netherlands Journal of Sea Research, 25(1-2):101$112,1990$.

[14] S. Zhang. Ecological roles of noctiluca scintillans in marine food web: as a predator, " prey" and nutrient regenerator. $\mathrm{PhD}$ thesis, 2016.

[15] S. Zhang, X. Xia, Y. Ke, S. Song, Z. Shen, S. Cheung, and H. Liu. Population dynamics and interactions of noctiluca scintillans and mesodinium rubrum during their successive blooms in a subtropical coastal water. Science of the Total Environment, $755: 142349,2021$.

Creative Commons Attribution License 4.0 (Attribution 4.0 International, CC BY 4.0)

This article is published under the terms of the Creative Commons Attribution License 4.0

https://creativecommons.org/licenses/by/4.0/deed.en_US 